\title{
A DYNAMIC SIMULATION/OPTIMIZATION MODEL FOR SCHEDULING RESTORATION OF DEGRADED MILITARY TRAINING LANDS
}

\author{
Hayri Önal ${ }^{1}$, Philip Woodford ${ }^{2}$, Scott A. Tweddale ${ }^{3}$, James D. Westervelt ${ }^{3}$, \\ Mengye Chen ${ }^{4}$, Sahan T.M. Dissanayake ${ }^{4}$, Gauthier Pitois ${ }^{4}$
}

1 (corresponding author) Department of Agricultural \& Consumer Economics, University of Illinois at Urbana-Champaign, $1301 \mathrm{~W}$. Gregory Dr., Urbana, IL 61822, USA, Phone: 1(217)3335507, Fax: 1(217)3335538, E-mail: h-onal@illinois.edu

${ }^{2}$ Woodford and Woodford, Inc., 2822 Tatarrax Dr., Manhattan, KS 66502-1971, USA

${ }^{3}$ U.S. Army Corps of Engineers, ERDC-CERL, P.O. Box 9005, Champaign, IL 61822, USA

${ }^{4}$ Formerly graduate research assistants in the Department of Agricultural \& Consumer Economics, University of Illinois at Urbana-Champaign

\begin{abstract}
:
Intensive use of military vehicles on Department of Defense training installations causes deterioration in ground surface quality. Degraded lands restrict the scheduled training activities and jeopardize personnel and equipment safety. We present a simulation-optimization approach and develop a discrete dynamic optimization model to determine an optimum land restoration for a given training schedule and availability of financial resources to minimize the adverse effects of training on military lands. The model considers weather forecasts, scheduled maneuver exercises, and unique qualities and importance of the maneuver areas. An application of this approach to Fort Riley, Kansas, shows that: i) starting with natural conditions, the total amount of training damages would increase almost linearly and exceed a quarter of the training area and 228 gullies would be formed (mostly in the intensive training areas) if no restoration is carried out over 10 years; ii) assuming an initial state that resembles the present conditions, sustaining the landscape requires an annual restoration budget of $\$ 957$ thousand; iii) targeting a uniform distribution of maneuver damages would increase the total damages and adversely affect the overall landscape quality, therefore a selective restoration strategy may be preferred; and iv) a proactive restoration strategy would be optimal where land degradations are repaired before they turn into more severe damages that are more expensive to repair and may pose a higher training risk. The last finding can be used as a rule-of-thumb for land restoration efforts in other installations with similar characteristics.
\end{abstract}

Key words: military training, land damages, rehabilitation, simulation, optimization 


\section{Introduction}

Degradation of training lands is an important issue for military installations. Land degradation reduces the ability of training lands to support the scheduled training activity and poses serious risks for the personnel and training equipment. Land degradation also affects the environment and ecosystem services in and around training lands through soil erosion and lowered water quality. In this paper, we introduce a decision support system involving a simulationoptimization model to minimize the adverse effects of a given training schedule by determining an optimal restoration of the damaged training lands over space and time. As a case study we apply the model to Fort Riley, Kansas. With appropriate modifications, the approach we introduce here can be applied to other installations that face similar land restoration challenges.

Several types of land degradation have been identified for Fort Riley: 1) maneuver damages, 2) gully formation, 3) damaged stream crossings, 4) damaged terraces/diversions, and 5) damaged roadside drainage ditches (ITAM Report, Fort Riley). The types of land damages listed above can be equally important at different times and different locations. In this paper, we focus on maneuver damages and gully formation only. These are the most common types of land degradation at all military maneuver-support installations and directly linked to training activity. Moreover, maneuver damage and gully formation have a causality relationship that justifies their joint consideration. Maneuver damages may result from each training event particularly due to heavy vehicle traffic that can create ruts and rills. This causes topsoil loss and destruction of the root system of ground vegetation cover, which in turn decreases the land's ability to resist further damages. If not repaired/restored (by land leveling, compacting, seeding, and mowing), such damages may turn into runoff channels and eventually develop into deep gullies that may cause further soil loss (USDA, 2002). Presence of gullies in a training area can be dangerous for fast moving vehicles especially when the gullies are hidden by tall vegetation and cannot be seen by vehicle operators. This increases training risk and leaves less area usable for future training (Diersing et al., 1988). Gullies are leveled, re-graded, and if necessary rock checks are installed to prevent further erosion. The area can then be reseeded and mulched as required (Figure 1).

The objective of the military land management is to maintain the quality and safety of the training areas to the extent possible. Maintaining the training lands in good condition requires significant manpower, equipment, and financial resources to repair maneuver damages and fill 
gullies ${ }^{1}$. The two land management activities are intertwined, namely repairing the damaged training lands proactively may reduce the potential for gully formation, which in turn reduces or eliminates some of the gully repairs and related costs that would occur otherwise. Ideally it may be optimal to repair any land damage whenever it occurs, but this may not always be feasible. The availability of financial resources for land repairs is the primary limitation. Even if adequate financial resources are available, gullies may still form due to unfavorable weather conditions, such as severe continued rainfall and flood, which may physically restrict repair activities. In such cases, damages can be repaired at a later time that is convenient for the land managers. In any time period, an optimal land management strategy may involve a combination of these two options, namely repairing some of the damaged lands and filling some gullies to the extent allowed by resource availability and weather factors. Thus, we state the research problem as follows: for a given annual training schedule and resource availability, determine a dynamic optimum land restoration strategy, specifically when, where and how much damaged land and how many gullies should be repaired/restored, to maintain and improve the quality of the military training areas.

\section{Methodology}

The relationship between military training activities and land degradation is a key factor when making land restoration decisions. The dynamics of land conditions and quantifying the impacts of off-road military vehicle use on land degradation are complex issues. Existing land and water management simulation models developed for agricultural systems (e.g., SWAT and EPIC ${ }^{2}$ ) are not much useful for this since they deal with the impacts of controlled and systematic operations (e.g., tillage, irrigation) whereas military training exercises are of a completely different nature because of their irregularity and randomness. Since the introduction of the Land Conditions and Trend Analysis Program (LCTA) in mid-1980's, numerous studies addressed this issue and a fairly large literature has evolved (see, for example, Diersing and Severinghaus, 1984; Wilson, 1988; Diersing et al., 1992; Haugen et al., 2003; Anderson et al., 2005; Wang et al., 2009; Wang et al., 2014; Howard et al., 2014). The relationship between training and land damage impacts is assessed using repeated experiments at selected plots (e.g., Althoff and Thien 2005) or

\footnotetext{
${ }^{1}$ The Fort Riley ITAM Report estimates that the cost of repairing a single acre of damaged land can be as much as $\$ 980$ (in 1993 values). Based on Landsat satellite images, the estimated damaged area was 7,180 acres, which would lead to a total cost of approximately $\$ 2.2$ million to repair maneuver damages that are predicted to occur in 2011.

${ }^{2}$ See http://swat.tamu.edu/documentation/ and http://epicapex.tamu.edu/manuals-and-publications/.
} 
considering different types of vehicles at a certain site (e.g., Jones et al. 2005). Several studies focused on natural characteristics, such as soil erosion properties (Althoff et al., 2007; Singer et al., 2012), soil wetness (Althoff and Thien, 2005), and vegetation cover (Greene and Nichols, 1996). Besides natural factors, some studies found that land conditions also depend on spatial intensity and temporal frequency of training activities (Howard et al., 2013) and continuous intensive training exercises on disturbed lands (Wang et al., 2014).

While the studies mentioned above narrowed our knowledge gap regarding the impacts of military training on land conditions, the effective use of this information in land management decision making has been lacking (Morrison-Saunders and Bailey, 2003; Anderson et al., 2005). This is mainly due to the fact that the existing models require very specific data, such as vehicle type, vehicle speed, maneuver path, tightness of turns, soil type, soil moisture, etc., whereas a typical training exercise involves these factors in various forms simultaneously and on multiple training sites with different characteristics. Therefore, the allocation of land restoration effort in military installations is usually based on the subjective judgment and experience of the land managers or broad guidelines utilizing the map of prevailing land conditions ${ }^{3}$. Such allocations may be sub-optimal and can lead to a serious loss in training efficiency. The only study that addressed the optimal allocation of restoration effort is presented by Tucker et al. (1998). In that study, a linear programming (LP) model is used to minimize the total cost of land rehabilitation and damage under a budget constraint. The model considers alternative rehabilitation options (rest, minor repair, moderate repair, and intense repair) for different land categories (grassland, shrubland, and woodland), where each rehabilitation option is assigned a cost per unit of the treated area. As the cost of damage, the model employs an 'incomplete rehabilitation cost' per unit of the damaged areas wherein training continues without rehabilitation. This cost is defined as the difference between the optimal cost under a budget constraint, derived from the LP, and the total cost of full rehabilitation without considering the budget limitation. The model determines how much of each land category should be rehabilitated by using each restoration option in order to minimize the total cost including the costs of rehabilitation and incomplete rehabilitation.

To some extent, the approach we use in the present paper is similar to the approach used by Tucker et al. (1998). Most notably, we also minimize the total 'cost' of unrepaired damages

\footnotetext{
${ }^{3}$ The percent ground cover (GC) is often used as a proxy for land conditions (e.g. Wang et al., 2009).
} 
using a mathematical programming model, where the cost (or 'disutility') is a surrogate for the training efficiency loss and risk. However, there are major differences between our methodologies because of the nature of issues addressed here. First, Tucker et al. have not explicitly incorporated the dynamics of training and damage events, thus ignored the cumulative impacts of continuous training. Instead, to account for cumulative damages they multiplied the cost of incomplete training by a scalar greater than one. In our model, training-induced land damages accumulate over time according to specified rules if training continues in the damaged areas. Consideration of the time factor, the causality relationship between training and land degradation, and the cumulative nature of training damages requires a multi-period dynamic modeling approach instead of a static LP approach. Second, under severe weather conditions cumulative damages can lead to gully formation that has not been included in the analysis by Tucker et al. Gullies have different implications than ordinary land damages in terms of management costs, training safety/efficiency, and environmental quality. We incorporate a rulebased causality relationship between ordinary surface damages and gully formation, and include an explicit cost for each unrepaired gully. Thus, essentially we consider unrepaired gullies as another form of incomplete restoration. However, because of their discrete nature, incorporating gully formation in the analysis requires a different modeling technique than used by Tucker et al. A unique feature of the model we present here is the dynamic simulation of if-then-else type discrete processes along with continuous processes. For instance, although land degradation occurs gradually and defined as a continuous variable, gully formation is a discrete event that can occur only if the cumulative degradation exceeds a specified threshold and if a strong storm occurs. Similarly, the damage resulting from a given training activity in a given area becomes more severe when the cumulative damage in that area exceeds a threshold damage level. These relationships cannot be expressed by using explicit functional forms as in conventional mathematical programming models. To deal with this complexity, we define binary variables for each time period and each training unit to determine whether those conditions are satisfied, and introduce multiple constraints to determine the associated conditional outcomes. This leads to a linear mixed-integer programming model.

Determining a dynamic optimal land management plan while considering the seasonality in training schedule and stochastic weather events is a complicated problem because at the time a restoration plan is to be determined the weather forecasts beyond the first few time periods 
would be highly uncertain. The longer the planning horizon, the more uncertain the weather forecasts, thus the projected damage impacts. This suggests considering a short time horizon when optimizing the land management activities. On the other hand, considering a very short planning horizon would undermine the possibility of land damages and gully development beyond that horizon. To cope with this issue, we consider a 'reasonably short' planning horizon and use an iterative 'rolling horizon' procedure. Specifically, at each iteration the optimum land restoration is determined in such a way that the total cost of all damages resulting from a given training schedule is minimized assuming that the weather forecast prevails throughout the planning horizon. Such a solution is a tentative plan in the sense that the decision for the first time period will be implemented by the land managers (an immediate response) while the optimal plans for the subsequent periods may be revised in light of new weather forecast that will be available in subsequent iterations. Therefore, after running the model for one planning horizon, we update the input data including cumulative damages in individual land units and weather forecasts, then move the horizon one period forward and rerun the model. We repeat this iterative procedure until the entire year is encompassed. Unlike deriving an annual plan by use of a fully deterministic optimization model, the rolling horizon approach mimics the actual decision making process more closely and develops an annual plan sequentially in light of new information about stochastic weather events and state of the landscape before making land management decisions in any period. Figure 2 depicts this iterative procedure assuming an eightweek planning horizon.

\section{An Overview of the Model}

The optimization model includes two key decision variables: i) the amount of damaged training lands to be restored, and ii) the number of gullies to be repaired in each time period and each training area. We assume that an annual training schedule is given a priori and the timing and location of training exercises will not be altered in consideration with the possible adverse impacts on landscape quality, which means implicitly that the land management task is subordinate to the military training activities. This assumption is consistent with the current practice and crucial in the model development ${ }^{4}$. A given training activity scheduled for a given

\footnotetext{
${ }^{4}$ Optimizing the training schedule and landscape management simultaneously may be considered as the ultimate approach to the problem. It may be possible to reschedule training both spatially and temporally without any loss of training benefits, but the mathematical formulation of the problem would be much more complex than the one presented here.
} 
time period on a particular training land unit may cause different maneuver damages depending on: i) the state of the landscape in that area prior to the current period training, which is characterized by previous land damages and repairs, and ii) weather (precipitation) conditions prevailing in that period. Therefore, the dynamics of landscape quality and stochastic weather events are incorporated explicitly in the model. Besides the scheduled training activities and weather conditions, training damages also depend on the cumulative damages and repair activities in individual training units (Wang et al., 2014). Therefore, we define the cumulative amount of damaged lands and the number of gullies formed over time as additional endogenous variables for each period and each training land unit. Normally, every period of a training year is equally important; therefore, the cumulative damages and gullies developed over time should be given equal importance. However, at each iteration of the simulation procedure we place more emphasis on the first few time periods of the rolling horizon because the weather information and related damages are more reliable for those periods than later time periods in that horizon.

At Fort Riley, some training areas are more frequently used than others and require more attention due to their unique characteristics which make them more suitable for certain training activities. Therefore, we assign different weights to individual training land units. A higher weight assigned to a particular land unit implies that repairing the damages that would occur on that unit is of higher priority; thus, those units would be repaired (to the extent possible) before repairing other land units with lower priority.

The mathematical model used in the empirical analysis is rather complex because of several relationships between the model variables governing the land degradation and gully development processes. Below, for the sake of readability we present the core of the model only; a detailed algebraic description of the full model is given in the appendix. For convenience, we use capitalized symbols for the decision variables and lower case symbols for data and parameters.

The objective function is defined as the total cost (or 'disutility' representing the perceived training efficiency loss/risk) of unrepaired training damages summed across all training land units and all time periods, which is to be minimized. This is stated as follows:

$$
\text { Minimize } \sum_{t, l} w_{t}^{*} p_{l} *\left\{v d * C D_{t, l}+v g * C G_{t, l}\right\}
$$


where $t$ and $l$ denote individual time periods and training land units; $w_{t}$ and $p_{l}$ denote the time weight assigned to period $t$ and repair priority assigned to land unit $l ; C D_{t, l}$ and $C G_{t, l}$ represent the cumulative maneuver damage and the total number of gullies defined for land unit $l$ and time period $t$. The two types of damages, measured in different units, are converted into a common unit by use of the conversion factors $v d$ and $v g$ which represent the disutility values associated with maneuver damages and gullies. The conversion factors can be quantified explicitly, based on the contribution of damaged lands and unrepaired gullies to the total cost of training, or they can be specified subjectively based on the perceived risks of maneuver damages and gullies in terms of training efficiency and safety.

Two sets of constraints are used in the model to simulate the dynamics of training damages in each training land unit and each time period. The first set is related to maneuver damages while the second set is related to gully formation. These constraints determine together the expansion/contraction of damaged lands and the resulting number of gullies in any period depending on the previous land damages and restoration activities.

The cumulative damage in a given training area in any time period is determined by the previous cumulative damage, the new maneuver damage, and the amount of repaired land in that unit. This is expressed as follows:

$$
C D_{t, l}=C D_{t-1, l}+M D_{t, l}-R D_{t, l} \text { for all } t, l
$$

where $t-1$ means the previous period, $M D_{t, l}$ and $R D_{t, l}$ are the amounts of maneuver damage and repaired damage in time period $t$ and land unit $l$. The maneuver damage variables are determined by the type of scheduled training activity, precipitation and soil saturation level in each area and time period (for details see the appendix).

Similarly, the dynamics of gully formation is expressed as:

$$
C G_{t, l}=C G_{t-1, l}+N G_{t, l}-R G_{t, l} \text { for all } t, l
$$

where $C G_{t, l}, N G_{t, l}$, and $R G_{t, l}$ denote the cumulative number of gullies, new gullies, and repaired gullies in time period $t$ and land unit $l$.

The last two components of the core model are the financial resource limitation and manpower constraints, given by (4) and (5) below. The first of those constraints restricts the cost of land restoration and gully repair activities to the available budget. The second constraint restricts the amount of labor needed to perform those operations to the available amount of labor 
that can be used directly to perform those operations. The ability and effectiveness of the land managers also depend on weather conditions, in particular severe and continued rainfall, which may limit the land restoration activities. Therefore, the manpower availability is specified differently for each period. The resource constraints are as follows:

$$
\begin{aligned}
& \sum_{l}\left\{d c * R D_{t, l}+g c * R G_{t, l}\right\} \leq b \text { for all } t \\
& \sum_{l}\left\{d l * R D_{t, l}+g l * R G_{t, l}\right\} \leq l b_{t} \text { for all } t
\end{aligned}
$$

where $d c$ and $g c$ denote the costs per unit of land restoration and per gully repair; $d l$ and $g l$ denote the labor needed to repair one unit of land and repair a gully; and $b$ and $l b_{t}$ denote the total amount of financial and manpower availability in time period $t$.

For simplicity, in the above model one type of gully is assumed. In the empirical model we distinguish between two sizes of gullies, namely small and large gullies, because of their different impacts on training safety and different resource requirements for repairing those gullies. Therefore, the endogenous variables representing the cumulative number of gullies, new gullies, and repaired gullies are defined for each gully category separately and incorporated in (1), (4) and (5). Also, equation (3) is stated for each gully category separately. All gullies are assumed to be small gullies at the time they are developed. If not repaired and unfavorable weather conditions occur, a small gully may grow into a large gully. Therefore, in equation (3) we include additional variables that represent the number of small gullies transformed into large gullies (subtracted from the total number of small gullies and added to the number of large gullies, see the full model). The development of gullies in any land unit is assumed to be related to the simultaneous occurrence of heavy precipitation and severe training damage. Specifically, a gully can occur in a given land unit only if the precipitation exceeds a threshold rainfall level and the amount of damaged land in that unit exceeds a threshold percentage of the total area of that unit. Growth of small gullies into large gullies is described in a similar way. These if-then-else type conditional relationships are formulated by use of multiple constraints including binary variables. The specific details are lengthy; for readibility they are given in the appendix.

Finally, the signs and the types of the model variables are restricted by:

$$
C D_{t, l}, M D_{t, l}, R D_{t, l} \geq 0 \text {, and } C G_{t, l}, N G_{t, l}, R G_{t, l} \geq 0 \text { integer for all } t, l
$$


The core model described by (1)-(6) is a mixed-integer linear program (MILP). The full model includes a large number of additional constraints and variables to describe the conditional statements related to the land damage and gully development processes.

\section{Data and Model Specification}

In the simulations presented below, we considered an annual time scale and weekly periods as the time unit for management decisions. Thus, the resource availability and the training schedule are specified on a weekly basis and the optimal land repair activities are determined for each week and each training area. In the rolling horizon procedure we considered an eight-week planning horizon at each iteration.

The entire installation of Fort Riley is partitioned into 78 discrete training areas with known boundaries on which tracked and wheeled training exercises occur. The sizes and boundaries of individual training areas were determined from the installation training area map in GIS. The amount of trainable land in each training area was determined by using a mask in GIS to eliminate all areas within 10m of a stream or water body. Based on the frequency of individual training areas used for actual training exercises in the past, an importance (priority) index is assigned to each training area (see Figure 3).

As training-induced land damages we consider ground surface disturbances and gullies that may result from such disturbances. For the first, we developed approximate damage impacts based on field knowledge and the understanding of simulation model applications. We assumed a fixed annual training schedule (with weekly time periods) for each training area considering typical historical training operations on that area. The training activities are categorized in three groups, light, medium, and heavy, based on the number of training days, number of troops, and number of vehicles involved in each training activity. The potential land damage, expressed as percentage increase in disturbed training land, is specified for each training type and adjusted for soil moisture depending on normal and severe weather conditions. For gullies, based on Hutchinson and Hutchinson (2014), we specified the maximum number of gullies that can develop in each training area depending on the slope, vegetation cover, and soil type.

As the adverse effects of unrepaired land damages on military training (the parameters $v d$ and $v g$ in the objective function of the model), we assigned disutility values to one acre of damaged land and one gully (specified differently for small and large gullies). The values of 
these parameters are based on subjective estimates of Fort Riley land managers ${ }^{5}$ and represent the relative importance of land damages in terms of training efficiency loss. In the resource constraints, we use the costs of repairing one acre of damaged land and repairing one gully (again specified differently for each gully type), and the manpower needed for such repairs. The costs are based on the engineering repair estimates by Fort Riley land managers. The annual restoration budget, specified exogenously, is assumed to be divided equally among weeks. However, unused budget can be carried over from one week to the next ${ }^{6}$.

With the spatial and temporal specifications described above, the resulting model is a large-scale linear mixed-integer program ${ }^{7}$ which is solved by using a commercial optimization software, General Algebraic Modeling Systems (GAMS) (Brooke et al., 1988) incorporated with CPLEX 12.5.1.0 ${ }^{8}$.

\section{Empirical Results}

We first calibrated the model $^{9}$ so that the cumulative damages and their spatial distribution closely simulate the landscape damage conditions in Fort Riley seen through the evaluation of 1993 orthophotography of the installation. For this, we ran the model ten times assuming the 1983-1993 meteorological data reported by the closest weather station to Fort Riley. We also assumed that the landscape was in pristine conditions (no previous damages) at the beginning of the 10-year simulation, the same training schedule was implemented in each year, and no repair activities were carried out (very few repairs actually occurred during that time). In each of those runs, we repeated the rolling horizon simulation-optimization procedure where the initial conditions of the current run were set at the ending conditions of the previous run.

\footnotetext{
${ }^{5}$ Alternatively, we could consider the increased cost of training in an area with such land damages, but those costs would be very difficult to estimate.

${ }^{6}$ Because of space limitation and for the sake of readability, a thorough documentation of the input data and specific assumptions made when generating the data are not given here. These are available upon request from the authors.

7 The following 'statistics' (copied from the GAMS output) give an idea about the model size: Single Equations= 16,085, Single Variables =12,497, Discrete Variables =7,410. Despite the sheer size of the model, GAMS/CPLEX could solve the problem efficiently. Usually, a model run during each iteration of the rolling horizon procedure takes a few minutes of processing time on a personal computer. The entire simulation took a little more than an hour.

${ }^{8}$ CPLEX, developed by IBM ILOG, is a high-performance mathematical programming solver for linear programming, mixed integer programming, quadratic programming, and quadratically constrained programming problems (http://www-01.ibm.com/software/commerce/optimization/cplex-optimizer/). As the optimality criterion we used $1.5 \%$ relative optimality. This means that if the best available solution is within the range of $1.5 \%$ deviation from the best possible solution, the solution is reported as the optimal solution.

${ }^{9}$ A former Fort Riley land manager (Dr. P. Woodford, co-author of the paper) was directly involved in the data compilation and model calibration processes.
} 
Figures 5 displays the 10-year simulation results for cumulative training damages. The figure shows an almost linear progress in training damages for each of those ten years. In some time periods the damages are more significant than others because of the more severe precipitation in those periods. An important observation is that the incremental damages decrease over time. This is due to the way training damages are modeled, namely initial damages on undisturbed lands are high, but repeated training causes less incremental training damage. The final value of cumulative training damages in the entire installation slightly exceeds 10,000 acres, which corresponds to nearly 25 percent of the total training land available in Fort Riley.

Based on the 10-year observed weather data and the resulting maneuver damages, a total of 228 gullies would be formed over time (Figure 6). Of those, 194 would be small while the remaining 34 would be large. Like the cumulative surface damages, the number of gullies increases according to a piecewise linear trend, except in year-7. In that year, the number of small gullies turning into large gullies exceeds the number of new small gullies, which is why the graph turns down. All gullies are small in the early years, but beginning in year-4 some of those gullies become large gullies when the maneuver damages reach the threshold levels and precipitation becomes favorable.

The spatial distribution of damaged training lands and gullies is displayed in Figure 7 for some benchmark years. As expected, extensive training damages occur in the south central section of the installation (the dark shaded spatial units) where more intensive training takes place. Therefore, small and large gullies develop also in the same area. These results imply that repairing the training damages and gullies must be of higher priority in that area in order to maintain the effectiveness and safety of training activities.

When a nonzero land restoration budget is considered, we expect that some of the maneuver damages and/or gullies can be repaired to the extent allowed by the budget availability. Three questions are addressed in this case: 1) should priority be given to repairing maneuver damages or repairing gullies, or both? 2) when and where would it be optimal to repair maneuver damages and gullies? and 3) what would be the smallest budget level needed to achieve a landscape without any gullies linked to maneuver damage?

To answer the above questions we changed the amount of budget availability in constraint (4) systematically and solved the model. The simulations demonstrate the role of financial resources in maintaining the landscape quality through repairing maneuver related 
damages. The results in Figure 8a indicate that the first $\$ 500$ thousand can effectively reduce the unrepaired training damages by nearly 3,000 acres, but the next $\$ 500$ thousand can reduce only half of that amount. Except in one case (with $B=1,500$ ), the effectiveness of financial resource availability decreases as larger budget levels are assumed. Figure $8 \mathrm{~b}$ shows the impact of budget availability on the total number of gullies (including both small and large gullies) that would exist in the entire installation. As in the case of maneuver damages, a higher budget level would lead to a smaller number of gullies. However, unlike in the case of maneuver damages, the progress of gully formation over time is not linear; rather there are ups and downs. In year-8 of the simulation, for instance, the number of gullies is reduced significantly under all budget levels. This is due to the milder weather conditions in that year which was not as suitable for gully formation as in the other years. However, a larger budget level again reduces the number of gullies as in the other simulations.

An important finding that should be emphasized is that, regardless of the budget availability, it is better to spend most (if not all) of the financial resources for repairing damaged lands rather than for fixing the gullies that could form otherwise (Figure 9). Although the disutility of one acre of damaged training land is substantially lower than the corresponding value per gully, the model suggests that priority should be given to the former in order to minimize the overall disutility. In other words, a proactive restoration strategy where maneuver damages are repaired before they lead to gully formation is optimal. This somewhat unintuitive result is due to the fact that reducing the amount of maneuver damages by land restoration also reduces the number of gullies that may develop otherwise. The empirical results show that this is a more cost-efficient way to achieve training effectiveness and personnel/equipment safety ${ }^{10}$.

In the above analysis land damages are valued differently across the training areas; namely some areas are assumed to be more important than others due to the need for intensive and frequent training in those areas. This makes land restoration more concentrated in those areas in terms of either repairing maneuver damages and/or gullies. An alternative management scheme may be to spread the restoration effort in space as uniformly as possible so that the landscape in the entire installation will be 'equally trainable'. This can be accomplished by imposing a constraint that restricts the unrepaired maneuver damages and gullies to be

\footnotetext{
${ }^{10} \mathrm{We}$ should note, however, that this result depends on the relative disutilities and repair costs associated with maneuver damages and gullies. Typically, gully repairs would cost substantially more (the cost of filling a small gully is five times the cost of repairing one acre of damaged land; the respective ratio for large gullies is 25:1).
} 
distributed as uniformly as possible among the training areas. Even if the total amount of maneuver damages and the number of gullies in the entire installation may be the same or close under the two management schemes, their location and concentration can be significantly different. Under the first management scheme, some areas with higher spatial weighting may receive more attention and restoration effort while some other areas may be put aside ${ }^{11}$. Assigning equal importance to all areas would deploy the restoration effort in such a way that the entire landscape will be of uniform quality in terms of maneuver damages and unrepaired gullies density. In the present application we perform this analysis for gullies only, although the same approach could be used for maneuver damages also, or both.

To incorporate the uniform spread criterion, we add the following constraint:

$$
C G_{t, l} \leq D^{*} a_{l} \text { for all } t, l
$$

where $D$ is a decision variable representing the gully density, which we use as a measure of the degree of trainability, and $a_{l}$ is the size of training area $l$. The right hand side of (7) represents the largest number of gullies allowed and the left hand side is the number of gullies (in the empirical application small and large gullies combined) in area $l$ and period $t$. The lower the value of $D$, the higher the trainability; thus, the model should minimize the value of $D$ together with the total disutility resulting from training damages. This is accomplished by having $D$ multiplied by a large penalty parameter as an additive term in the objective function (1). By doing so, the model would not allow a large concentration of gullies in some areas while many other high priority areas are relatively free of gullies.

The development of gullies in the optimal solution of the uniform spread model is depicted in Figure 10, which shows the year-end total number of gullies for each year of the simulation horizon. This graph is similar to the graph in Figure $8 \mathrm{~b}$ (unrestricted optimum solution) except that the number of gullies in some years is slightly higher. More importantly, the two solutions are significantly different in terms of the spatial distributions of gullies. To illustrate those differences, the gully development in two different training areas, labeled by L53 and L48, is shown below. The shaded rows correspond to the unrestricted case, where spatial weighting is assigned to individual training areas, while the rows below them correspond to the case where gullies are restricted to be spread 'uniformly' across space. Under the first scheme

\footnotetext{
${ }^{11}$ This characterization is termed as the 'hot spots' problem in environmental management. Thus, the above formulation aims to avoid the presence of hot spots to the extent possible.
} 
area L53 is a 'hot spot' where 12 gullies are present at the end of the simulation, whereas in the uniform-spread scheme the number is reduced to seven to make the gully density across all areas nearly the same. On the other hand, in the spatial weighting scheme five gullies are present in area L48, whereas in the uniform-spread scheme eight gullies are present in that area.

\begin{tabular}{|c|c|c|c|c|c|c|c|c|c|}
\hline & S2 & S3 & S4 & S5 & S6 & S7 & S8 & S9 & S10 \\
\hline L53 & & 4 & 1 & 6 & 8 & 9 & 1 & 11 & 12 \\
\hline L53 & & 4 & 2 & 7 & 8 & 9 & 5 & 12 & 7 \\
\hline L48 & & 3 & 1 & 4 & 5 & 6 & 1 & 7 & 5 \\
\hline L48 & 1 & 3 & 1 & 5 & 6 & 6 & 6 & 8 & 8 \\
\hline
\end{tabular}

The previous analysis assumes that the entire landscape was in its natural (pristine) condition at the beginning of the simulation (i.e., no maneuver damages and related gullies were present). The initial training damages in such a landscape would be substantially larger than the damages that would occur after repeated training in the same areas because preference is given to previously trained areas and lands with training damages expand only if the new damages exceed the repaired amounts of previously damaged lands. Therefore, the damaged areas expand fast in the beginning, but at a slower rate in later time periods. When a significant portion of the training area has been damaged already, the optimal management plan may be quite different from the optimal plan for an initially natural landscape. In this case, preventing gully formation through controlling the expansion of damaged training lands would have limited effectiveness since the disturbed lands are already present; therefore, gullies can form even if very little or no new damage occurs. This is the current state of the landscape in Fort Riley. Under such circumstances, one may expect that in the optimal strategy more resources might be devoted to repair gullies. We use the model to analyze this situation and determine an optimal land management strategy that maintains the status quo. In this analysis we focus on gullies only; therefore, the goal implies that no new gullies will be added to the system. This can be accomplished by performing appropriate land restoration activities and/or by repairing an appropriate number of gullies so that the total number of gullies in the entire training area remains the same. The repaired gullies may be either new gullies (repaired within the period in which they develop) or existing gullies. Sustaining the number of gullies in the entire landscape may require a significant amount of financial and manpower resources depending on the duration and frequency of bad weather conditions during the intensive training periods. Our purpose is to 
determine the annual budget and manpower requirements to keep the landscape in 'steady state' condition.

To generate a proxy to the initial state we first ran the simulation model for a 10 -year planning horizon considering the observed annual weather patterns and assuming that no land repairs have been performed throughout those ten years. Thus, initially there were 228 gullies, of which 194 were small and 34 were large; 110 of the small gullies and 28 of the large gullies were in the high priority areas. In the new simulation run, we considered a one-year simulation horizon and assumed the weather pattern in year-1 of the 10-year weather data as the prevailing weather.

Table 1 presents some highlighted results for the training areas with the highest priority. The first important finding is that in most of those areas the number of gullies (especially small gullies) is reduced by one or two (in a few areas by three). In order to sustain the gully numbers, in the optimal steady state solution the model allows development of one or two gullies in some other areas with lower priority (mostly in the eastern section of the installation, see Figure 3). At the end of the simulation, the total number of small gullies was reduced to 188 while the number of large gullies was increased to 40 . Still there were 228 gullies in the entire installation, but the number of small gullies was slightly fewer while the number of large gullies was slightly larger. Furthermore, the spatial distribution of the gullies was altered significantly ${ }^{12}$. The required amount of financial and manpower resources would be $\$ 956.8$ thousand for the whole year and 16 people in the busiest repair period. As expected, only a small amount of the budget, \$11.8 thousand, would be spent for restoring the damaged lands while the rest was spent for gully repairs.

\section{Conclusions}

Maneuver training lands are arguably the most valuable aspect of the Army installations. These lands are difficult to expand or acquire and must be cared for to ensure long-term safe and realistic training. The modeling efforts described in this paper were developed to support installation natural resource managers, trainers, and headquarter level officers responsible for maintaining and using maneuver areas across the country.

\footnotetext{
${ }^{12}$ An important assumption here is that when a gully in a given training area is repaired, the maximum number of gullies that can develop in that area is reduced by one.
} 
An important finding of this research that should be emphasized is that, regardless of the budget availability, it is better to spend most (if not all) of the financial resources for repairing damaged lands rather than for fixing the gullies that could form otherwise. In other words, a proactive restoration strategy where maneuver damages are repaired before they lead to gully formation is optimal. The empirical results show that this is a more cost-efficient way to maximize training effectiveness and personnel/equipment safety. If the relative importance of land damage categories and the relative costs of repairing those damages are representative, this result can be used as a rule of thumb for other training facilities.

Installation Integrated Training Area Management (ITAM) offices could use the model to help schedule the use of available funding, personnel, and equipment to optimally repair gullies and tracked maneuver areas. In the application presented here, maneuver training activities (type and location of training) are provided as fixed inputs. The model could also be used to establish and justify budget requests by comparing the level of maneuver area damage that remains after considering a range of repair funding levels. Minimal funding levels can be identified that will ensure that the maneuver areas do not degrade further from current or otherwise defined levels. These analyses can be conducted on an annual or a week-to-week basis. The test applications described in this paper demonstrate analyses on an annual scale. By running the model with many examples of historic weather, it becomes possible to identify the range of risk damages associated with varying financial inputs. The model can also be used on a weekly basis to schedule range rehabilitation work in a given week given the training schedule and the weather forecast for that week. Local ITAM managers can use the model as a decision support tool and update the model from the previous week by identifying 1) the work that was accomplished in the previous week, and 2) the latest weather forecast for the current and subsequent weeks.

At a headquarter level that oversees the funding resources that will be made available across many installations, the model can be used to allocate funds optimally and to identify and justify funding requests. To accomplish these goals, model input data would be developed for a set of installations (consisting of historic/projected weather, current damage, and expected training schedules). Then, running the model for each installation using ranges of potential funding amounts, graphs could be developed to correlate funding levels with resulting damage levels. By considering all of the graphs across all of the installations, a budget allocation could 
be identified that results in equal damage levels across all installations, or allocations that realize desired/acceptable damage levels.

In the model developed here, training is considered to be an immutable given, resulting in a capability that allows ITAM offices to optimize the expenditure of rehabilitation funds. It is well understood that most of the damage to training lands occurs on the very few days when the soils across the training areas are wet. The wetter the soil, the deeper the rutting damage and greater the probability of the unrecoverable destruction of the plants and roots that provide resilience to maneuver training. With appropriate modifications, this model can be used to determine optimum scheduling of training and coordinating the training and land restoration activities, which can dramatically reduce rehabilitation expenditures and training-induced damages.

This study focused on land restoration activities considering the value of the managed lands in terms of military training risks only. There are simultaneous measurable environmental benefits of maintaining military training sites in good condition. Reducing the possibility of gully formation by restoring damaged land surfaces and repairing gullies reduce soil erosion and sediment runoff to nearby water bodies, which may have significant impact on water quality and wildlife habitats within the installation and in the surrounding areas ${ }^{13}$. Incorporating such benefits can be done by using a multi-objective programming approach where military training and environmental benefits are considered simultaneously as multiple objectives. Unlike in typical multi-objective problem situations, this is a case where the two objectives are largely complementary rather than conflicting.

Some of the parameters used to simulate the land degradation and gully formation processes are subjective estimates based on the experience and best judgement of a former land manager at Fort Riley. The values used in the empirical model were obtained after tedious calibration runs. A sensitivity analysis would be useful to see how the results would change if alternative values were used, but that was beyond the scope of this research.

When simulating the soil degradation and gully formation processes, the model treats all training areas in the same way, namely the new damage potential (new gully formation) is expressed as a percentage of the training area (number of existing gullies) and the same

\footnotetext{
${ }^{13}$ For example, the Topeka Shiner, a federally-endangered fish, has been found in four streams on the east side of Fort Riley. It is a protected species that has a large impact on ITAM. Also, 23 animal species considered rare in Kansas (including five reptiles or amphibians and three riverine fish) are present on the installation (ITAM Report).
} 
percentage parameters are used for all training areas (although the coefficients vary by training type and depend on the weather factor). In reality, some areas are more erodible than others (because of the slope, soil type, vegetation conditions, etc.), thus using different coefficients for different parts of the installation would be more meaningful. The damage impacts reported here should be interpreted with this oversimplification in mind.

Acknowledgments: This study is partially supported by the US Army Engineer and Development Center and Construction Engineering Research Laboratory (CERL Agreement W9132T-10-2-0016 and the USDA National Institute of Food and Agriculture, 34 Hatch Project No. ILLU 05-0361. 


\section{References:}

Althoff, D.P. and Thien, S.J. (2005). Impact of M1A1 main battle tank disturbance on soil quality, invertebrates, and vegetation characteristics. Journal of Terramechanics, 42:159176.

Althoff, D.P., Althoff, P.S., Lambrecht, N., Gipson, P.S., Pontins, J.S., and Woodford, P.B. (2007). Soil properties and perceived disturbance of grasslands subjected to mechanized military training: evaluation of an index. Land Degradation \& Development, 18: 269-288.

Anderson, A.B., Palazzo, A.J., Ayers, P.D., Fehmi, J.S., Shoop, S., and Sullivan, P. (2005). Assessing the impacts of military vehicle traffic on natural areas. Introduction to the special issue and review of the relevant military vehicle impact literature, Journal of Terramechanics, 42: 143-158

Brooke, A., D. Kendrick, A. Meeraus, and R. Raman. GAMS: A User’s Guide, 1988. [Documentation of the User's Guide for recent releases is available at GAMS Development Corporation official site http://www.gams.com/l

Diersing, V. E., Shaw, R. B., Warren, S. D. and Novak, E.W. (1988). User's guide for estimating allowable use of tracked vehicles on non-wooded military training lands. Journal of Soil and Water Conservation, 43:191-195.

Diersing, V. E. and Severinghaus, W. (1984).The effects of tactical vehicle training on the lands of Fort Carson, Colorado - an ecological assessment. United States Army Construction Engineering Research Laboratory, Champaign, IL [TR N-85/03].

Diersing, V. E., Shaw, R. B. and Tazik, D. J (1992). US Army Land Condition-Trend Analysis (LCTA) Program. Environmental Management, 16: 405-414.

Fang, S., Wente, S., Gertner, G.Z., Wang, G., Anderson, A.B. (2002). Uncertainty analysis of predicted disturbance from off-road vehicular traffic in complex landscapes at Fort Hood. Environmental Management, 30:199-208.

Green, T.A. and Nichols, T.J. (1996). Effects of Long Term Military Training Traffic on Forest Vegetation in Central Minnesota. Northern Journal of Applied Forestry , 13:157-163.

Hutchinson, S. and S. Hutchinson (2014). Validating the kinematic wave approach for rapid soil erosion assessment and improved best management practice site selection to enhance training land sustainability, Final report for ESTCP Project RC-200820. February 2014. 
URL:http://oai.dtic.mil/oai/oai?verb=getRecord\&metadataPrefix=html\&identifier=ADA602 246

Haugen, L.B., Ayers, P.D., Anderson, A.B. Vehicle movement patterns and impact during military training exercises. Journal of Terramechanics, 40:83-95.

Howard, H.R., Wang, G., Singer, S., and Anderson, A.B. (2013). Modeling and prediction of land condition for Fort Riley military installation. Transactions of the ASABE, 56:643-652.

Integrated Training Area Management (ITAM) Report, Fort Riley, KS (with permission from US Army Corps of Engineers, ERDC-CERL)

Jones, R., Horner, D., Sullivan, P., and Ahlvin, R. (2005). A methodology for quantitatively assessing vehicular rutting on terrains. Journal of Terramechanics, 42: 245-257.

Morrison-Saunders, A. and Bailey, J. (2003). Practitioner perspectives on the role of science in environmental impact assessment. Environmental Management, 31:683-95

Singer, S., Wang, G., Howard, H., Anderson, A. (2012). Environmental condition assessment of US military installations using GIS based spatial multi-criteria decision analysis. Environmental Management, 50; 329-340

Tucker J.L., Rideout, D.B., Shaw, R.B. (1998). Using linear programming to optimize rehabilitation and restoration of injured land: an application to US army training sites. Journal of Environmental Management, 52:173-182.

USDA. 2002. Estimating soil loss from gully erosion - ephemeral or classic, June 2002. https://efotg.sc.egov.usda.gov/references/public/MO/gully-ephemeral_erosion.pdf

Wilson, S. (1988). The effects of military tank traffic on prairies: a management model. Environmental Management, 12:397-403

Wang, G., Gertner, G., Anderson, A.B., Howard, H.R. (2009). Simulating spatial pattern and dynamics of military training impacts for allocation of land repair using images. Environmental Management, 44:810-823

Wang, G., Murphy, D., Oller, A., Howard, H.R., Anderson, A.B., Rijal, S., Myers, N.R., and Woodford, P. (2014). Spatial and temporal assessment of cumulative disturbance impacts due to military training, burning, haying, and their interactions on land condition of Fort Riley, Environmental Management, 54:51-66 


\section{APPENDIX}

\section{DESCRIPTION OF THE FORT RILEY LAND MANAGEMENT MODEL}

The model is an integer programing model that simulates the land managers' decision making process in light of a given annual training schedule, weather conditions and the dynamic processes that govern maneuver damages and gully formation in the training areas. The critical decisions are the amount of land to restore and the number of gullies to repair in each training area and each time period. The constraining factors are financial and manpower availabilities to perform the planned restoration/repair activities. The first is determined by the annual budget allocated to land rehabilitation operations, the second is determined by the crew size and weather factors which may restrict site accessibility and the number of work days available for restoration activities (excluding off site preparation, office work, etc.) in each time period.

The notation used for variables and parameters is described when presenting the individual equations of the model. For convenience, the decision variables are denoted in upper case symbols while the exogenous parameters are denoted in lower case symbols. Indexes used in variable definitions and constraints are: $t$ for time periods; $l$ for training areas; $r$ for training intensity (low, medium, high).

Objective function:

$$
\text { Minimize } \sum_{t, l} w_{t} * p_{l} *\left(v d * C D_{t, l}+v s g * C S G_{t, l}+v l g * C L G_{t, l}\right)
$$

where $w_{t}$ is the time weight assigned to period $t ; p_{l}$ is the land restoration priority assigned to training area $l ; v d, v s g$, $v l g$ are the safety values per unit of maneuver damages, small and large gullies, respectively; $C D_{t, l}$ is the cumulative amount of damaged land in area $l$ and period $t$; $C S G_{t, l}$ and $C L G_{t, l}$ are the number of small and large gullies present in area $l$ and period $t$ (after subtracting endogenous land/gully repairs).

The objective function, to be minimized, is a weighted sum of the maneuver damages and gullies that may develop across all training lands and throughout the planning horizon. The weights are used to convert the land damages and gullies (measured in acres and counts) into a common unit. These can be based on the costs of reversing those damages or can be specified subjectively to reflect the importance of those damages in terms of training safety. 
Maneuver damages are determined by two factors: 1) soil wetness (saturation) related to the intensity of rainfall in the current and previous periods, and 2) type of training. The amount of damage is expressed as a percentage of the trainable area in each training area where the proportionality factor depends on the intensity of the scheduled training activity and the soil saturation. If the soil saturation exceeds a threshold level, the damage impact increases.

A causal relationship is hypothesized between the amount of maneuver damages and gully formation. It is assumed that the total number of gullies that may develop in a given training area and time period depends on the largest area that was previously subject to maneuver damage. The justification for this assumption is as follows: typically training occurs in the areas used for training in previous periods; thus, if the current period maneuver damage does not exceed the repaired area it is a repeated damage, otherwise a new damage occurs. Surface repair/restoration makes damaged areas trainable again, but repaired/restored lands are as susceptible to gully formation as damaged lands. Thus, the area in which gullies may develop expands only if a positive new damage occurs. To accommodate this assumption, we define an effective damage variable $E D_{t, l}$ which denotes the cumulative new damages. In other words, the effective damage in time period $t$ is the largest damaged area up to period $t$. Note that while the cumulative damage variable $C D_{t, l}$ may increase or decrease, depending on the relative values of current period training damages and repairs, $E D_{t, l}$ is non-decreasing over time. The following constraints govern these relationships.

Land damage constraints:

$$
\begin{aligned}
& C D_{t, l}=C D_{t-1, l}+M D_{t, l}-R D_{t, l} \text { for all } t, l \\
& C D_{t, l}=E D_{t-1, l}+P D_{t, l}-N D_{t, l} \text { for all } t, l \\
& P D_{t, l} \leq m * B D_{t, l} \quad \text { for all } t, l \\
& N D_{t, l} \leq m *\left(1-B D_{t, l}\right) \text { for all } t, l \\
& E D_{t, l}=E D_{t-1, l}+P D_{t, l} \text { for all } t, l \\
& E D_{t, l} \leq t d^{*} t a_{l}+m * B T D_{t, l} \text { for all } t, l \\
& E D_{t, l} \geq t d^{*} t a_{l} * B T D_{t, l} \text { for all } t, l \\
& P M D_{t, l}=a_{l} * s s_{t} * s t_{l, t, r} *\left(h i_{r} *\left(1-B T D_{t, l}\right)+l i_{r} * B T D_{t, l}\right) \text { for all } t, l
\end{aligned}
$$




$$
\begin{aligned}
& P M D_{t, l}+C D_{t-1, l} \leq a_{l}+m^{*} B C D_{t, l} \quad \text { for all } t, l \\
& M D_{t, l} \geq a_{l} * B C D_{t, l}-C D_{t-1, l} \quad \text { for all } t, l \\
& M D_{t, l} \geq P M D_{t, l}-m^{*} B C D_{t, l} \quad \text { for all } t, l \\
& M D_{t, l} \leq P M D_{t, l} \quad \text { for all } t, l
\end{aligned}
$$

where $a_{l}$ is the trainable area in area $l ; s s_{t}$ is soil saturation factor in time period $t\left(s s_{t}=1\right.$ if biweekly rainfall is less than the threshold precipitation, else $\left.s s_{t}=2\right) ; s t_{t, l, r}$ is a binary scalar showing whether training type $r$ is scheduled for area $l$ in time period $t\left(s t_{t, l, r}=1\right.$ if yes, 0 if not); $h i_{r}, l i_{r}$ are the high and low damage impact factors, respectively, associated with training type $r$; $t d$ is a specified threshold damage level beyond which maneuver damage impact gets lower due to repeated damages; $m$ is an arbitrarily specified large number; $P M D_{t, l}, M D_{t, l}$, and $R D_{t, l}$ are potential maneuver damage, actual maneuver damage, and repaired damage, respectively, in area $l$ and time period $t ; D D_{t, l}$ is the difference between cumulative damage and the previous period's effective damage in area $l$ and time period $t ; B T D_{t, l}$ is a binary variable which shows whether the effective damage in parcel $l$ and time period $t\left(E D_{t, l}\right)$ exceeds the threshold damage level; $B C D_{t, l}$ is a binary variable which indicates whether in time period $t$ the effective maneuver damage hits the total trainable land in area $l$; all other symbols are as defined before.

Equation (2) simulates the dynamics of maneuver damages, namely the cumulative damage in any area equals the previous cumulative damage in that area, plus current period damage, minus repairs. Equation (3) states the relationship between cumulative and effective damage values. If the current period's cumulative damage exceeds the previous period's effective damage, some new damage must have occurred, otherwise the damage is a repeated damage and the effective damage remains the same. This property is modeled by defining auxiliary non-negative variables $P D_{t, l}$ and $N D_{t, l}$ which represent whether an incremental change has occurred in the damaged area, $P D_{t, l}>0$, or more repairs occurred than damages in area $l$ and period $t, N D_{t, l}>0$. Since one of these two cases can occur in any area and time period, either $P D_{t, l}$ or $N D_{t, l}$ must be zero. The effective damage $E D_{t, l}$ increases only when $P D_{t, l}>0$, as stated by (6). To guarantee that either $P D_{t, l}$ or $N D_{t, l}$ must be zero, we introduce constraints (4) 
and (5) and a binary variable $B D_{t, l}$. If $B D_{t, l}=1,(5)$ implies $N D_{t, l}=0$; otherwise $B D_{t, l}=0$ and (4) implies $P D_{t, l}=0$. In the first case (4) becomes redundant while in the second case (5) becomes redundant; thus at most one of the $P D_{t, l}$ and $N D_{t, l}$ variables can take a positive value. Equation (9) determines the potential damage that may result from training. If the effective damage in a given area does not exceed the threshold damage level, (8) implies that $B T D_{t, l}=0$. In this case the training area is relatively undisturbed and initial training activities would have a high damage impact. If the threshold level is exceeded, (7) implies that $B T D_{t, l}=1$, in which case the impact of training activities will be reduced. When the potential damage calculated by (9) plus the previous cumulative damage exceeds the total trainable land in a given area, the actual maneuver damage must be less than the potential damage. In this case, (10) implies that $B C D_{t, l}=1,(12)$ becomes redundant, and (11) and (13) together imply that $M D_{t, l}$ must be within the range $\left(a_{l}-C D_{t-1, l}, P M D_{t, l}\right)$. Minimization of the sum of damaged areas assigns the lowest feasible value, namely $M D_{t, l}=a_{l}-C D_{t-1, l}$, which is the remaining undamaged area. When the cumulative damage does not hit the area limit, then $B C D_{t, l}=0$, and (12) and (13) together imply $M D_{t, l}=P M D_{t, l}$, as it should be.

If maneuver damages are not repaired, gullies may develop as a result of severe precipitation and surface runoff. We assume that at the time a gully is formed, it is a small gully; if a small gully is not repaired and a severe weather occurs it may grow into a larger gully because surface runoff makes the gullies wider, longer, and deeper. Formation of gullies in a given training area and time period is related to three factors: 1) the maximum number of gullies that can develop in that area, 2) the amount of previous effective maneuver damage in that area, and 3) the intensity and duration of precipitation which determine the conditions for a flood and soil saturation level. The maximum number of gullies that may develop in an area is specified for each area differently based on the slope, ground cover, and soil characteristics of that area. If a gully is repaired, in the subsequent model runs the maximum number of gullies is reduced by one. If the effective maneuver damage does not exceed a threshold level or the total rainfall in a specified time window does not exceed a threshold precipitation level no gully can form, otherwise the number of gullies is determined by dividing the effective damaged land by the amount of damaged land required per gully. 


\section{Gully formation constraints:}

Dynamics of gully development are simulated by the following equations:

$$
\begin{aligned}
& C S G_{t, l}=C S G_{t-1, l}+N S G_{t, l}-R S G_{t, l}-G G_{t, l} \text { for all } t, l \\
& C L G_{t, l}=C L G_{t-1, l}+G G_{t, l}-R L G_{t, l} \text { for all } t, l
\end{aligned}
$$

where $N S G_{t, l}$ and $R S G_{l, t}$ are the number of new small gullies and repaired small gullies; $R L G_{t, l}$ is the number of large gullies repaired; and $G G_{t, l}$ is the number of small gullies growing into large gullies, in area $l$ and time period $t$. All other symbols are as defined earlier. Equation (14) states that the number of small gullies in a given area and time period is the number of small gullies in the previous period plus the number of new small gullies minus the number of repaired small gullies and small gullies transformed into large gullies. Similarly, Equation (15) describes the dynamics of large gully development.

We introduce binary variables to determine whether the conditions are favorable for gully formation. This is done by the constraints below:

$$
\begin{aligned}
& E D_{t, l} \leq t g * t a_{l}+m * B G D_{t+1, l} \text { for all } t, l \\
& E D_{t, l} \geq t g * t a_{l} * B G D_{t+1, l} \text { for all } t, l \\
& B G_{t, l} \geq B G D_{t, l}+b r_{t}-1
\end{aligned}
$$

where $t g$ is the threshold level (percentage) of effective maneuver damage for gully formation; $b r_{t}$ is a binary scalar, where $b r_{t}=1$ indicates that the threshold precipitation level required for gully formation is exceeded in period $t$, otherwise $b r_{t}=0 ; B G D_{t, l}$ is a binary variable which indicates that the threshold effective damage level is exceeded in area $l$ and period $t$, in which case $B G D_{t, l}=1$, otherwise $B G D_{t, l}=0$; and $B G_{t, l}$ is a binary variable which indicates that both maneuver damage and precipitation conditions are favorable for gully formation in area $l$ and period $t$, in which case $B G_{t, l}=1$, otherwise $B G_{t, l}=0$. To see how the above inequalities work, suppose the effective maneuver damage in area $l$ and period $t$ is not exceeded. Then $B G D_{t+1, l}=0$ satisfies both (16) and (17) and $B G_{t+1, l}=0$ satisfies (18) regardless of the precipitation level in period $t+1$. This means that gullies cannot form in that area in the next time period $(t+1)$. Conversely, suppose the effective maneuver damage exceeds the threshold level. 
Then, (16) implies $B G D_{t+1, l}=1$, which also satisfies (17). The remaining condition for gully formation is whether $b r_{t+1}=1$ or not. If $b r_{t+1}=1$, then both effective damage and precipitation conditions are met. In this case, (16) implies $B G_{t+1, l}=1$, as we should have. If the precipitation is not severe enough, i.e., $b r_{t+1}=0$, then $B G_{t+1, l}=0$ and $B G_{t+1, l}=1$ both satisfy (18). In order the model to choose $B G_{t+1, l}=0$ in the optimal solution, we multiply the $B G$ variables by a large penalty parameter and include it in the objective function as an additive term (not shown in (1)).

Once the two conditions for gully development are met, the number of potential gullies in area $l$ in any time period $t$ is determined by:

$$
\begin{aligned}
& P G_{t, l} \geq \frac{E D_{t, l}}{a p g_{l}}-1-m^{*}\left(1-B G_{t, l}\right) \text { for all } t, l \\
& P G_{t, l} \leq \frac{E D_{t, l}}{a p g_{l}} \text { for all } t, l \\
& P G_{t, l} \leq m^{*} B G_{t, l} \quad \text { for all } t, l
\end{aligned}
$$

where $\mathrm{apg}_{l}$ is the average maneuver damage per gully (total training land divided by maximum number of gullies) in area $l ; P G_{t, l}$ is a non-negative integer representing the total number of gullies that may exist in area $l$ in period $t$; and all other symbols are as defined earlier. If $B G_{t, l}=0$, (21) implies that no gullies can be formed in area $l$ and period $t$. Otherwise, $B G_{t, l}=1$, (19) and (20) assign the truncated integer value of $E D_{t, l} / a b g_{l}$ as the number of potential gullies. Note that because of constraint (20) the number of potential gullies in any time period cannot exceed the maximum number of gullies that can develop in a given area.

All gullies are small gullies when they are first formed, if the conditions are favorable for gully growth small gullies become large gullies. Once a small gully grows into a large gully, it remains as a large gully unless repaired. These properties are modeled by the equations:

$$
\begin{aligned}
& N S G_{t, l}=P G_{t, l}-\sum_{t^{\prime}<t} N S G_{t^{\prime}, l} \text { for all } t, l \\
& (22) \\
& G G_{t, l} \leq g g^{*} C S G_{t-1, l}-1 \text { for all } t, l \\
& G G_{t, l} \geq g g^{*} C S G_{t-1, l} \text { for all } t, l
\end{aligned}
$$


where $g g$ denotes the gully growth factor (percentage of small gullies growing into large gullies). Constraints (24) and (25) assign the truncated integer value of $g g * C S G_{t-1, l}$ as the number of small gullies that grow into large gullies.

$\underline{\text { Resource constraints: }}$

$$
\begin{aligned}
& \sum_{l}\left\{d l * R D_{t, l}+s g l * R S G_{t, l}+\lg l * R L G_{t, l}\right\} \leq l b \text { for all } t \\
& \sum_{l}\left\{d c * R D_{t, l}+s g c * R S G_{t, l}+\lg c * R L G_{t, l}\right\}+S B_{t} \leq b+S B_{t-1} \text { for all } t
\end{aligned}
$$

where $d l, s g l, \lg l$ are the labor requirements for repairing one acre of damaged land, one small gully, and one large gully; $d c, s g c, \lg c$ are the costs of repairing one acre of damaged land, one small gully, and one large gully; $l b, b$ are available manpower and land management budget that can be used for all land and gully repairs per unit time, and $S B_{t}$ is the unused budget carried over from period $t$ to period $t+1$. Constraints (25) and (26) restrict the use of manpower (labor) and financial resources to their availability in each period. 


\section{Figures and Tables}

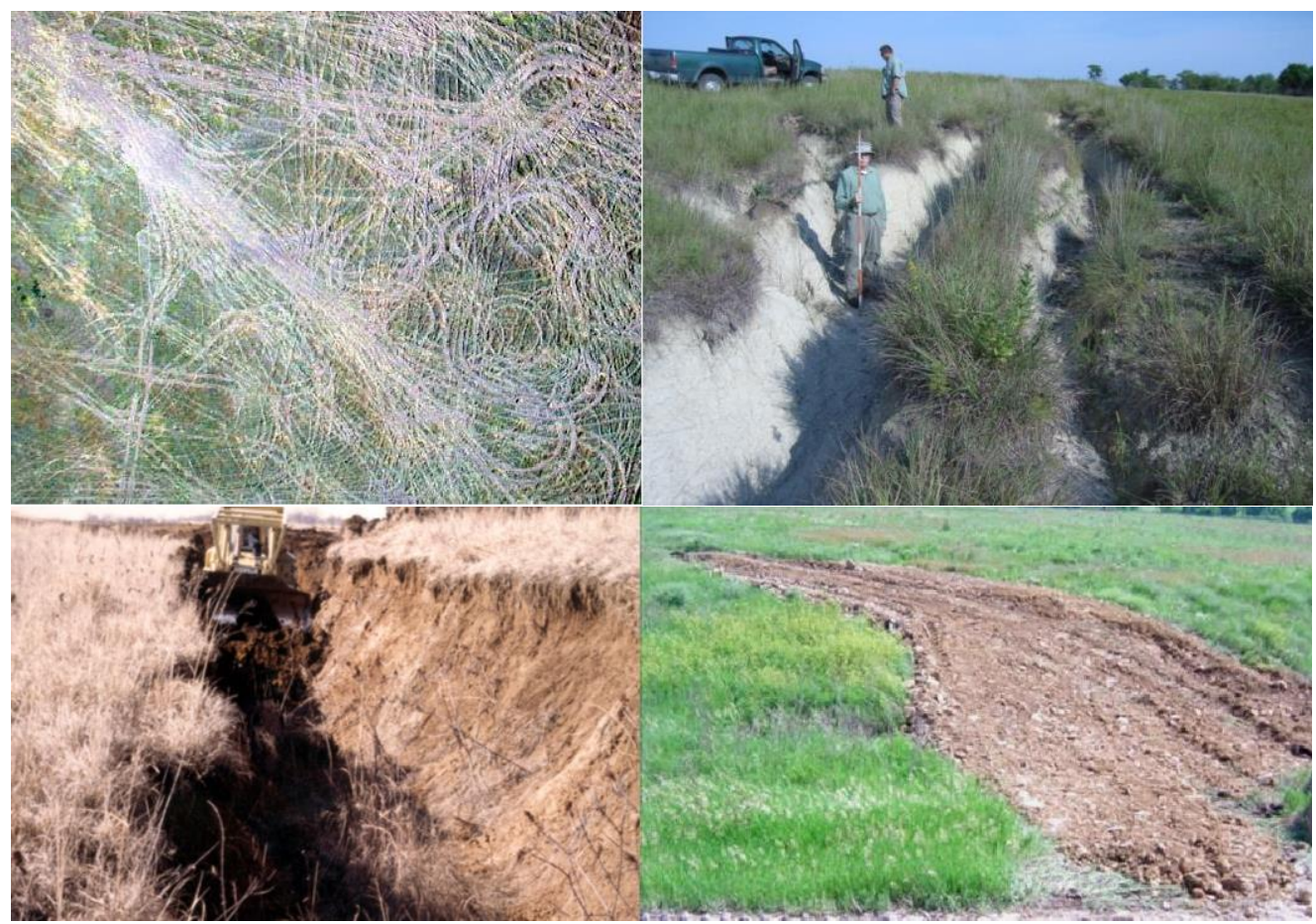

Figure 1: Aerial photo of maneuver damages (upper left), gullies formed due to military vehicle traffic and runoff (upper right and lower left), and a repaired gully (lower right).

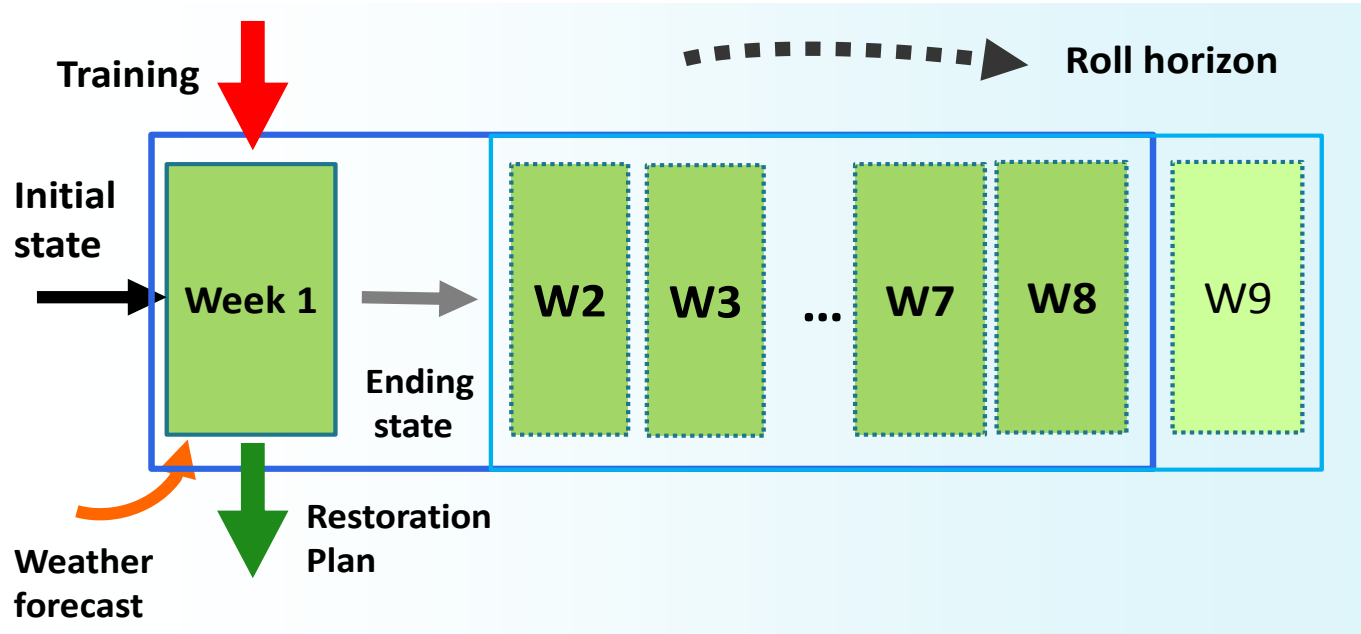

Figure 2: The rolling horizon approach to dynamic optimization. The box shown with bold solid lines represents an 8-week deterministic optimization problem assuming that the weather forecast for weeks W1-W8 represents the actual weather conditions throughout this period. Implementation of the optimal plan for week-1 determines the initial state of the system in the next iteration shown with lighter solid lines including weeks W2-W9 (dotted rectangles). 


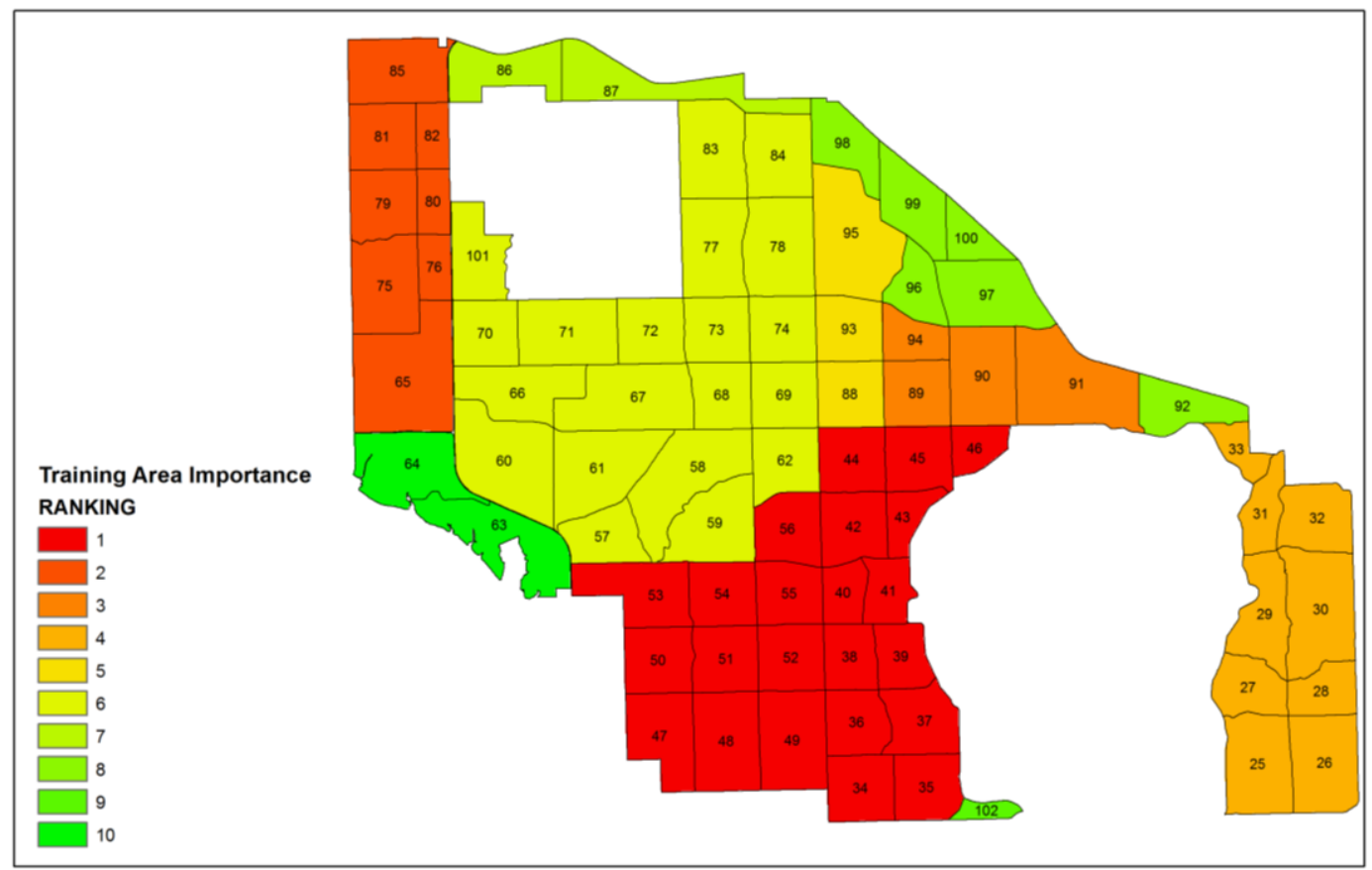

Figure 3: Restoration priority map (1=highest, 10=lowest)

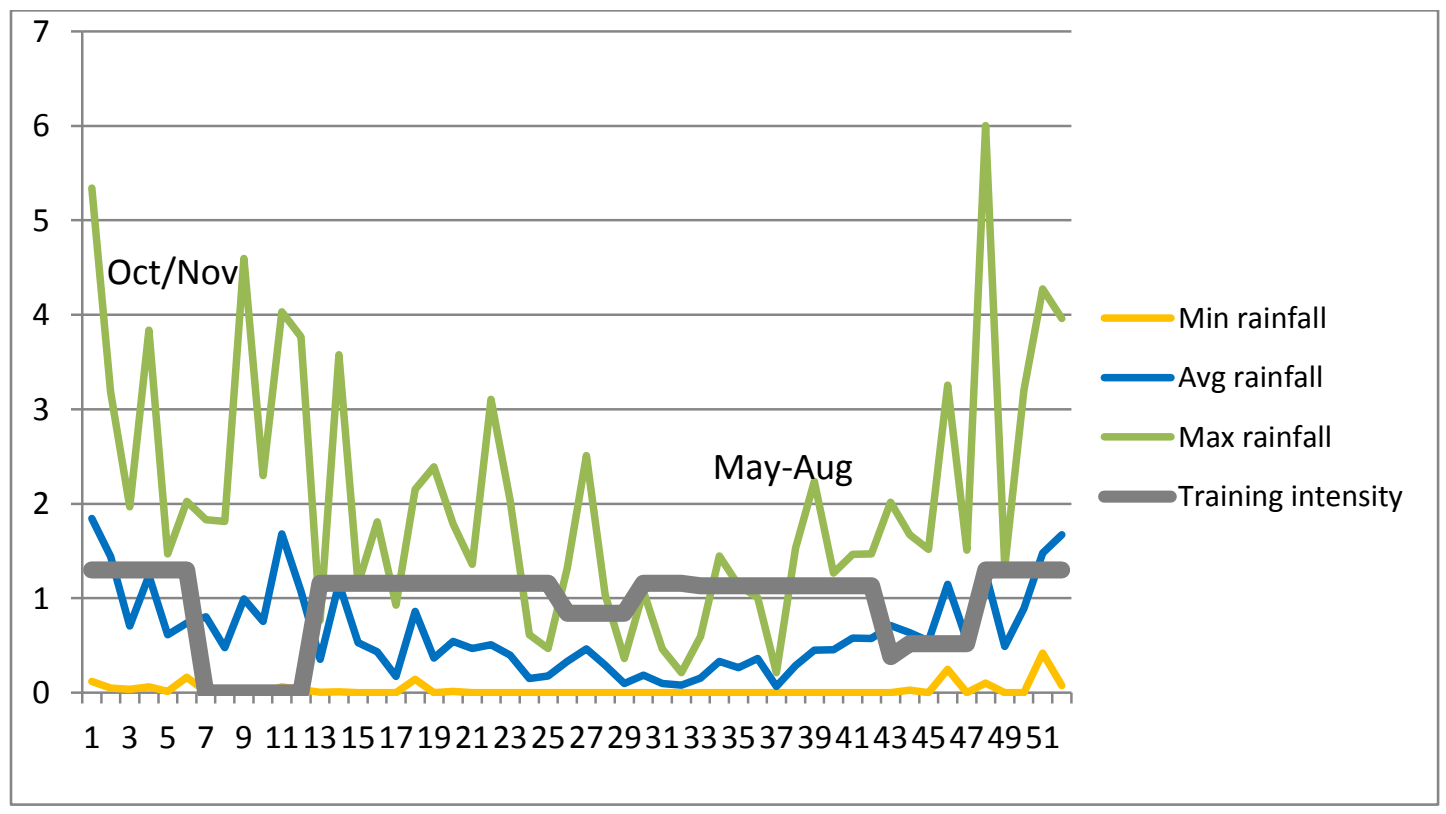

Figure 4: Annual rainfall pattern and training schedule 


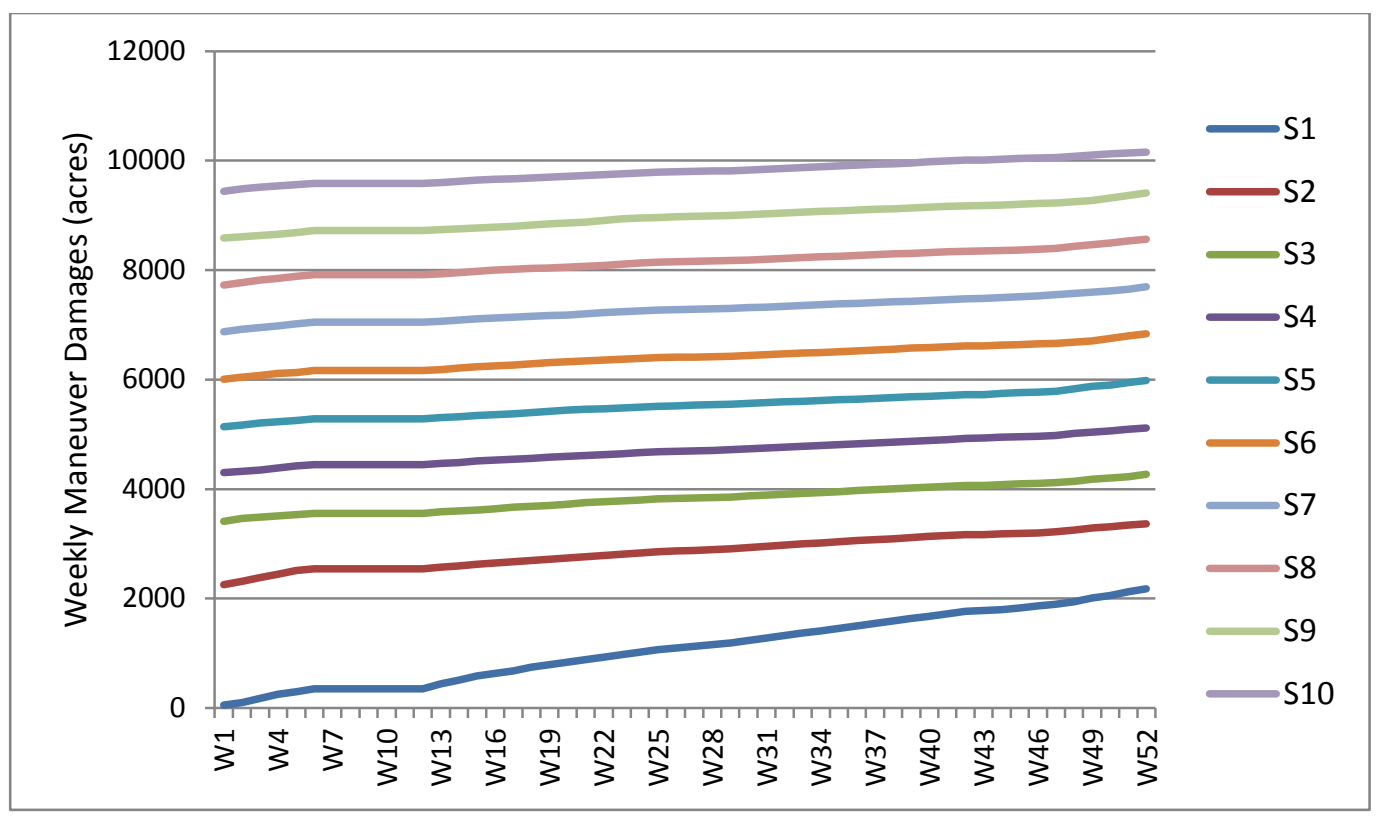

Figure 5: Cumulative weekly maneuver damages without repairs [Si represents simulation in year i]

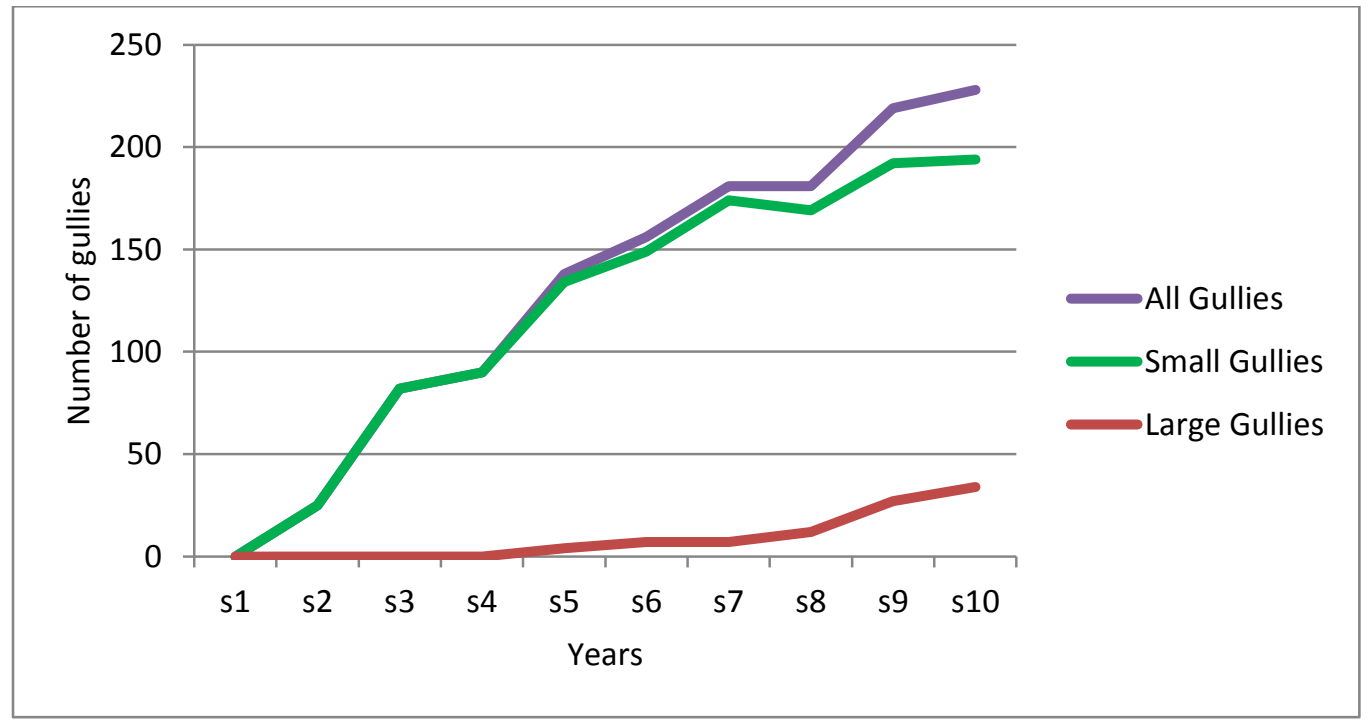

Figure 6: Progress in the development of gullies without land restoration 

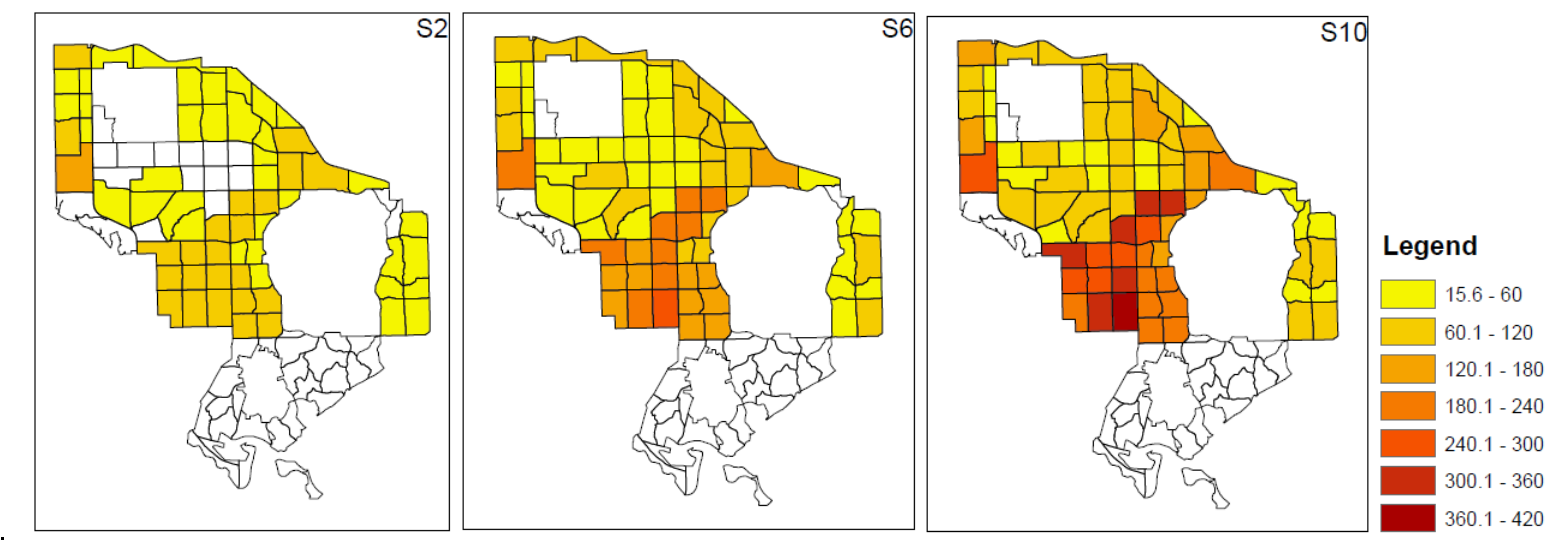

(7a)
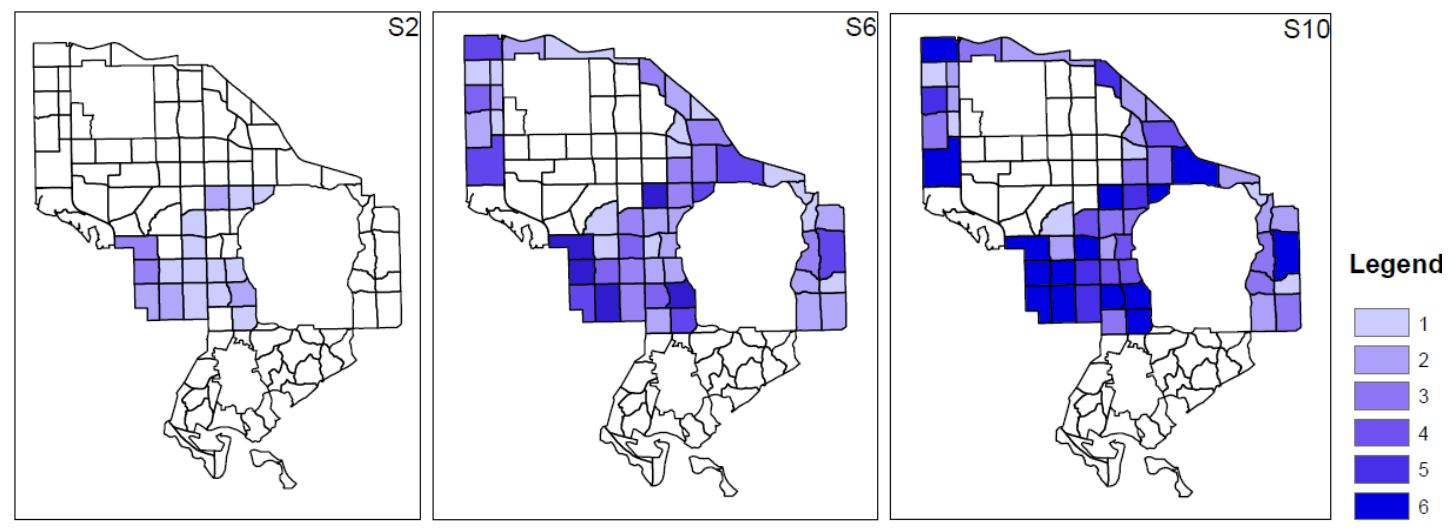

(7b)

Figure 7: Spatial distribution of cumulative maneuver damages (in acres), (7a), and small gullies, (7b), in benchmark years ( $\mathrm{Si}$ in the upper right corner of each figure represents simulation year i) 


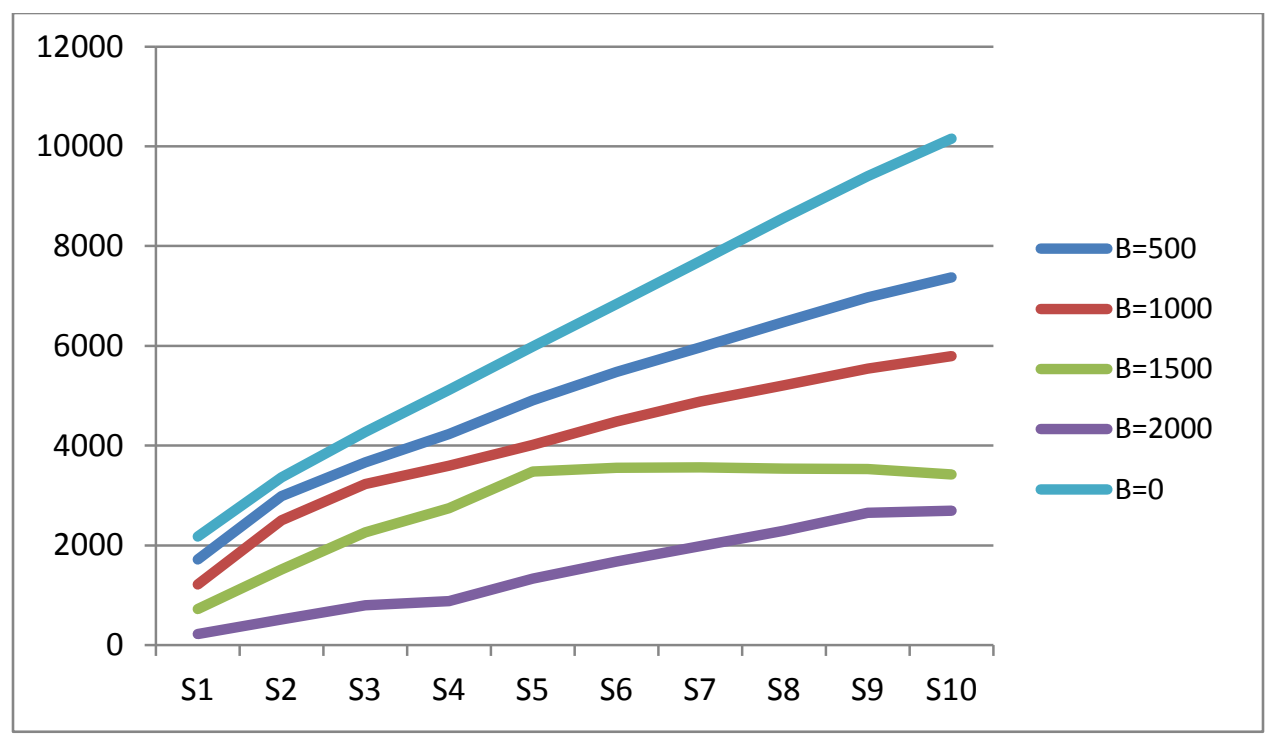

(8a)

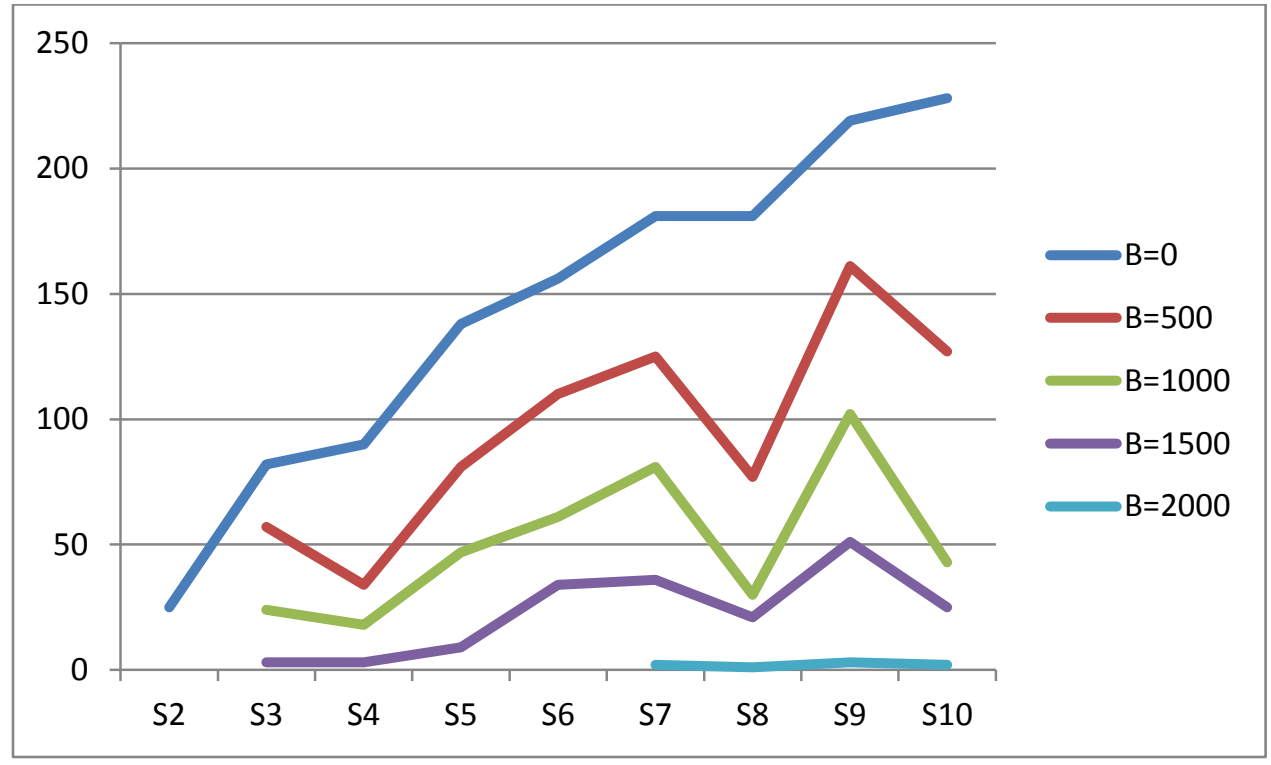

(8b)

Figure 8: Cumulative maneuver damages, (8a), and number of gullies, (8b), under different budget levels ( $\mathrm{B}$ in $\$ 1000$ ) 

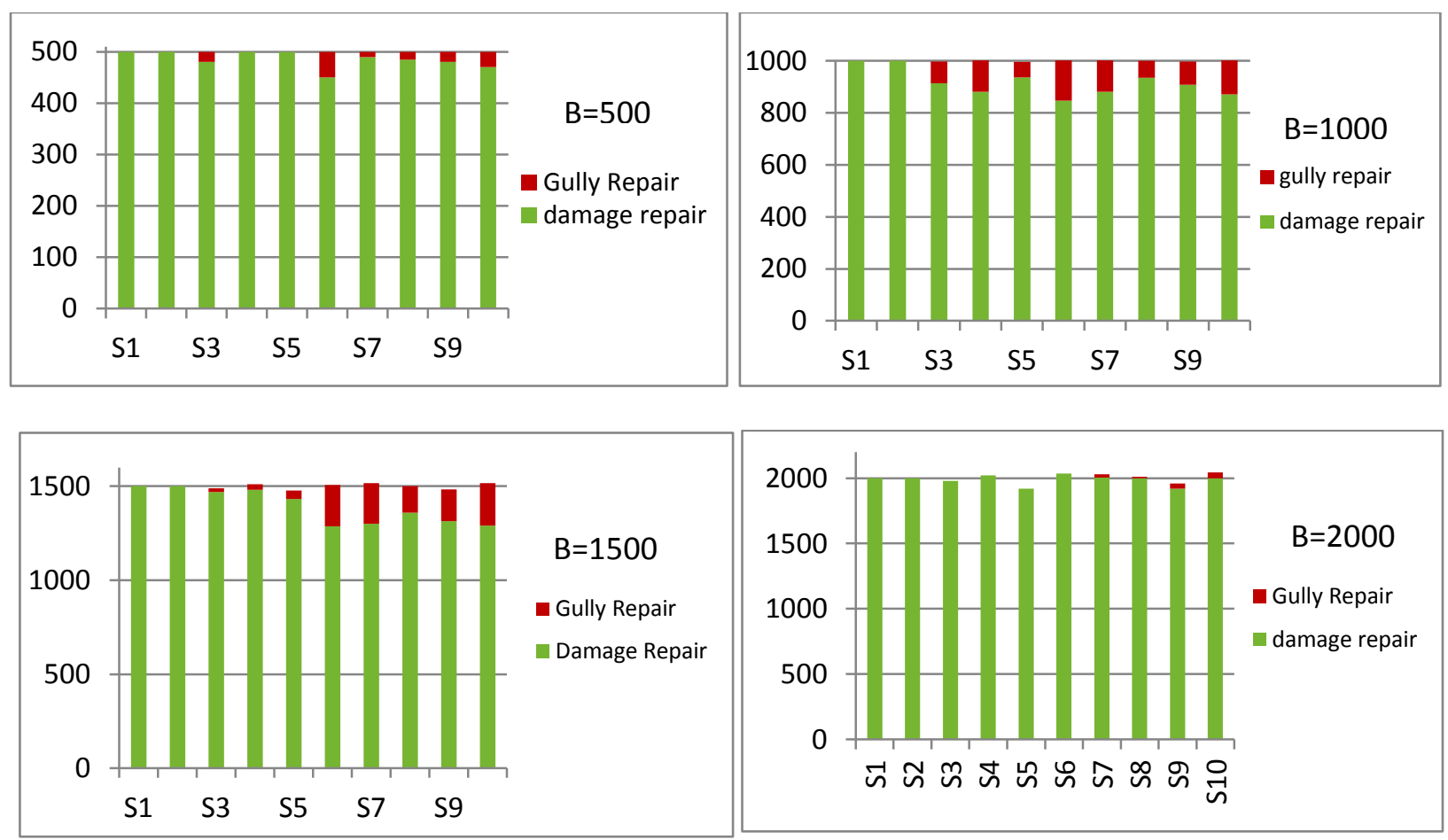

Figure 9: Spending for damage repairs and gully repairs (in \$1000)

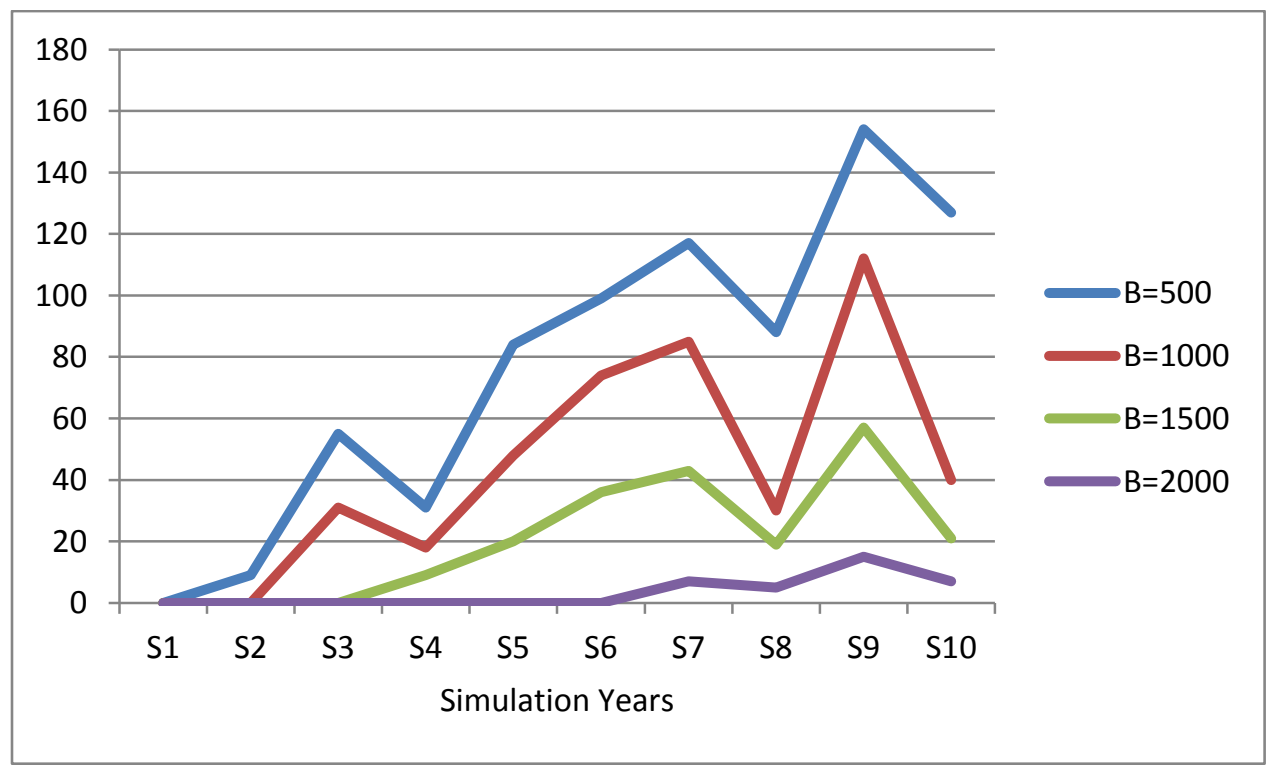

Figure 10: Cumulative number of gullies under different budget levels ( $\mathrm{B}$ in $\$ 1000$ ) without spatial weighting. 
Table 1: Number of gullies in selected training areas in the beginning and end of the simulation

\begin{tabular}{|c|c|c|c|c|c|c|}
\hline & Parcel Id & Initial/Final & Parcel Id & Initial/Final & Parcel Id & Initial/Final \\
\hline \multirow{8}{*}{$\begin{array}{l}\text { Small } \\
\text { Gullies }\end{array}$} & L34 & $3 / 2$ & L43 & $3 / 2$ & L51 & $6 / 4$ \\
\hline & L35 & $6 / 4$ & L44 & $6 / 4$ & L52 & $5 / 3$ \\
\hline & L36 & $6 / 4$ & $\mathrm{~L} 45$ & $5 / 3$ & L53 & $6 / 4$ \\
\hline & L37 & $6 / 3$ & L46 & $6 / 3$ & L54 & $2 / 1$ \\
\hline & L38 & $4 / 2$ & L47 & $6 / 3$ & L55 & $6 / 4$ \\
\hline & L39 & $4 / 2$ & $\mathrm{~L} 48$ & $6 / 4$ & L56 & $4 / 2$ \\
\hline & $\mathrm{L} 40$ & $2 / 1$ & L49 & $5 / 3$ & & \\
\hline & $\mathrm{L} 42$ & $3 / 2$ & $\mathrm{~L} 50$ & $6 / 4$ & & \\
\hline \multirow{2}{*}{$\begin{array}{l}\text { Large } \\
\text { Gullies }\end{array}$} & L35 & $1 / 2$ & L46 & $1 / 2$ & L50 & $7 / 8$ \\
\hline & L37 & $3 / 4$ & L47 & $1 / 2$ & L53 & $7 / 8$ \\
\hline
\end{tabular}

